\title{
Endoderme com atividade meristemática em raiz de Canna edulis Kerr-Gawler (Cannaceae) ${ }^{1}$
}

\author{
Alexandre A. Alonso ${ }^{2,4}$, Marina A. Moraes-Dallaqua ${ }^{2}$ e Nanuza L. de Menezes ${ }^{3}$
}

Recebido em 26/09/2003. Aceito em 10/03/2004

\begin{abstract}
RESUMO - (Endoderme com atividade meristemática em raiz de Canna edulis Kerr-Gawler (Cannaceae)). Canna edulis é uma planta ornamental utilizada em muitos países como fonte alimentar alternativa. O objetivo deste trabalho foi descrever a formação do córtex radicular a partir da análise anatômica da região apical. Na região situada a $220 \mu \mathrm{m}$ do pró-meristema, os tecidos meristemáticos apicais já se apresentam organizados em protoderme, meristema fundamental e procâmbio. Em fase subseqüente na diferenciação celular, a $450 \mu \mathrm{m}$ do pró-meristema, as camadas de células do córtex estão dispostas em fileiras radiais iniciando-se na endoderme. Depois que as iniciais endodérmicas cessam as divisões, adquirem estrias de Caspary. Na raiz, a 1.700 $\mu$ m do pró-meristema, os tecidos primários já se encontram diferenciados, sendo o padrão de distribuição celular observado no córtex de $C$. edulis característico ao apresentado por outras espécies de Zingiberales. A análise anatômica da região apical levou à constatação que 2/3 do córtex é resultante da atividade meristemática da endoderme e o restante das células corticais são originadas diretamente do meristema fundamental.
\end{abstract}

Palavras-chave: ápice radicular, Canna, endoderme com atividade meristemática

\begin{abstract}
Endodermis with meristematic activity in the root of Canna edulis Kerr-Gawler (Cannaceae)). Canna edulis is a ornamental plant used in many countries how alternative nutritional source. This work describes the development of the radicular cortex from anatomical observations of apical region. In the region situated at $220 \mu \mathrm{m}$ from the promeristem, apical meristematic tissues at once present themselves organized in protoderm, ground meristem and procambium. During the subsequent phase of cellular differentiation, at $450 \mu \mathrm{m}$ from the promeristem, cell layers of the cortex are arranged in radial tiers to be initiated in the endodermis, indicating the presence of meristematic endodermis activity. After finishing divisions, endodermic initial acquire Casparian strips. In the root at $1,700 \mu \mathrm{m}$ from of promeristem, primary tissues are immediately differentiated, the pattern of cellular distribution being observed in the cortex of Canna edulis, a characteristic of that is found in other species of Zingiberales. The anatomical observations lead to the conclusion that $2 / 3$ of the cortex is originated of endodermis with meristematic activity, and the remainder are originated from ground meristem.
\end{abstract}

Key words: root apex, Canna, endodermis with meristematic activity

\section{Introdução}

Dentre as monocotiledôneas, a ordem Zingiberales é claramente delimitada e aceita como grupo natural de oito famílias: Zingiberaceae, Costaceae, Marantaceae, Cannaceae, Lowiaceae, Musaceae, Heliconiaceae e Strelitziaceae (Dahlgren et al. 1985). Essas famílias incluem 89 gêneros e cerca de 1.800 espécies, sendo a família Cannaceae constituída apenas pelo gênero Canna L. com, aproximadamente, 50 espécies distribuídas pelas regiões tropicais do mundo (Castro 1995).

As espécies desse gênero são herbáceas e, pelo caráter decorativo de suas flores, são cultivadas como plantas ornamentais (Graven et al. 1997). Além de ornamental, Canna edulis é utilizada em muitos países como fonte alimentar alternativa, devido ao acúmulo de substâncias de reserva sob a forma de grãos de amido nos rizomas (Pérez et al. 1997).

As abordagens morfo-anatômicas de órgãos vegetativos de Canna são discutidas em um contexto taxonômico (Tomlinson 1961; 1962; 1969; Cronquist 1981; Dahlgren et al. 1985; Kress 1990). Em relação às descrições dos órgãos subterrâneos desse gênero, particularmente as referentes ao sistema radicular, essas descrições são apresentadas mediante observações da estrutura anatômica de raízes diferenciadas (Tomlinson 1961).

\footnotetext{
Parte da Dissertação de Mestrado do primeiro Autor

2 Departamento de Botânica, Instituto de Biociências, Universidade Estadual Paulista, C. Postal 510, CEP 18618-000, Botucatu, SP, Brasil (alonsoalx@yahoo.com.br; marina@ibb.unesp.br)

3 Departamento de Botânica, Instituto de Biociências, Universidade de São Paulo, C. Postal 11461, CEP 05422-970, São Paulo, SP, Brasil (nanuzalm@ib.usp.br)

4 Autor para correspondência: alonsoalx@yahoo.com.br
} 
Todavia, ao observar a estrutura anatômica desse órgão em C. edulis verificou-se que a interpretação a respeito da origem das células do córtex com disposição radiada seria possível por meio da análise da estrutura anatômica do ápice das raízes dessa planta. Sendo assim, o presente trabalho teve como objetivo descrever a formação do córtex radicular dessa espécie a partir da análise anatômica da região apical verificando a participação da endoderme neste processo, buscando aprimorar o conhecimento desse grupo de plantas.

\section{Material e métodos}

Os ápices radiculares foram coletados de plantas cultivadas sob condições de campo, em áreas do Departamento de Botânica, Instituto de Biociências UNESP, Botucatu, SP, sendo obtidas por meio de propagação vegetativa a partir de fragmentos de rizomas contendo a gema apical. Os propágulos foram fornecidos pela Equipe de Agricultura do Projeto Temático "Prospecção de Novos Amidos para a Indústria de Alimentos" do CERAT (Centro de Raízes e Amidos Tropicais), da Fazenda Experimental Lageado, UNESP, Botucatu, SP.

A amostragem para o estudo anatômico foi realizada por meio de fragmentos de $0,5 \mathrm{~cm}$ compr., totalizando $1 \mathrm{~cm}$ dos ápices radiculares. As amostras foram fixadas em solução de Karnovsky (Karnovsky 1965), desidratadas em etanol, pré-infiltradas e incluídas em resina glicol-metacrilato, segundo a técnica descrita por Gerrits (1964).

A estrutura anatômica dos ápices radiculares foi descrita por meio de secções tranversais e longitudinais seriadas, com $5 \mu \mathrm{m}$ de espessura. As secções foram coradas em Azul de toluidina a 0,05\%, em tampão acetato pH 4,7 (O'Brien et al. 1964) e as lâminas montadas com resina sintética. As fotomicrografias foram feitas em fotomicroscópio Zeiss (MC-80), com as escalas micrométricas fotografadas e ampliadas nas mesmas condições ópticas.

\section{Resultados}

O sistema radicular de Canna edulis é do tipo adventício (Fig. 1), com raízes formadas a partir do periciclo dos rizomas. $\mathrm{O}$ ápice radicular, em secção longitudinal mediana (Fig. 2), mostra o pró-meristema, constituído por um conjunto de células iniciais, observando-se, lateralmente, um grupo de derivadas que se dividem dando origem à protoderme e às células que formam o caliptrógeno. Envolvendo esse pró-

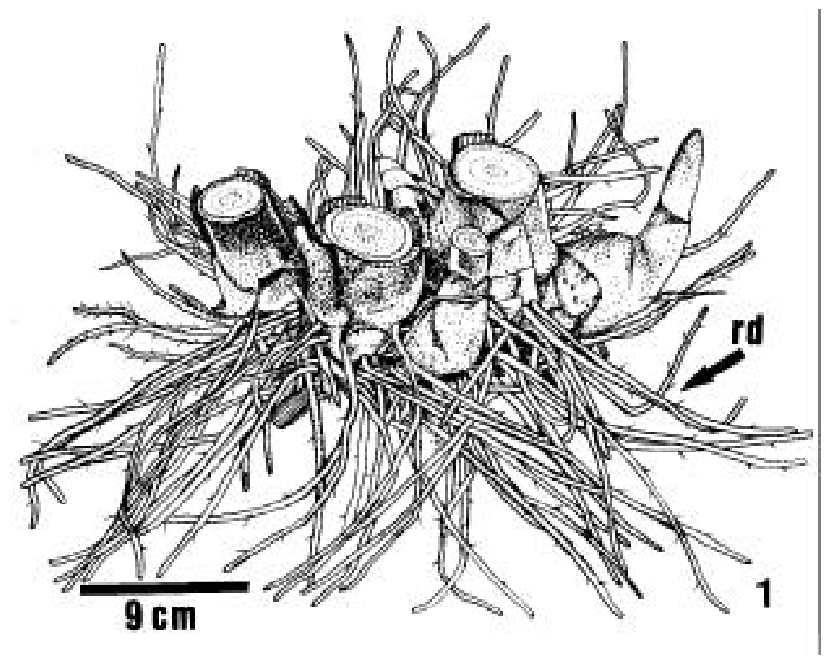

Figura 1. Raízes adventícias (rd) de Canna edulis Kerr-Gawler.

meristema, observa-se a coifa em diferenciação (Fig. 2), com suas células centrais dividindo-se em vários planos (Fig. 5).

As células derivadas do pró-meristema e situadas imediatamente acima das iniciais constituem as células do meristema fundamental e do procâmbio (Fig. 2, 5). Em seguida, inicia-se a diferenciação, com as células procambiais centrais começando a se alongar e tornando-se vacuolizadas. Perifericamente, destaca-se uma fileira de células, com citoplasma denso e núcleo evidente, que são as células do periciclo (Fig. 3).

$\mathrm{Na}$ Figura 2, observa-se que as células do meristema fundamental apresentam-se longitudinalmente alongadas. Essas células, posteriormente, irão constituir as camadas externas do córtex. Nessa região, as células da protoderme sofrem divisões anticlinais, diferenciando-se, posteriormente, em células epidérmicas (Fig. 4).

Na secção transversal da raiz de $C$. edulis a $220 \mu \mathrm{m}$ do pró-meristema, observam-se células da protoderme dividindo-se anticlinalmente (Fig. 6). O córtex é constituído de células distribuídas radialmente indicando origem a partir da endoderme (Fig. 6), evidenciada pelo aumento gradativo do tamanho das células. Tais células apresentam citoplasma denso, núcleo central e nucléolos evidentes. Internamente às iniciais endodérmicas observa-se, no cilindro vascular, o periciclo (Fig. 6), elementos traqueais e crivados em diferenciação.

A $450 \mu \mathrm{m}$ do pró-meristema, o cilindro vascular da raiz mostra células do procâmbio diferenciando elementos vasculares e periciclo. É possível perceber que as células iniciais endodérmicas (Fig. 7, 8), após divisões periclinais para formar as fileiras radiais de 


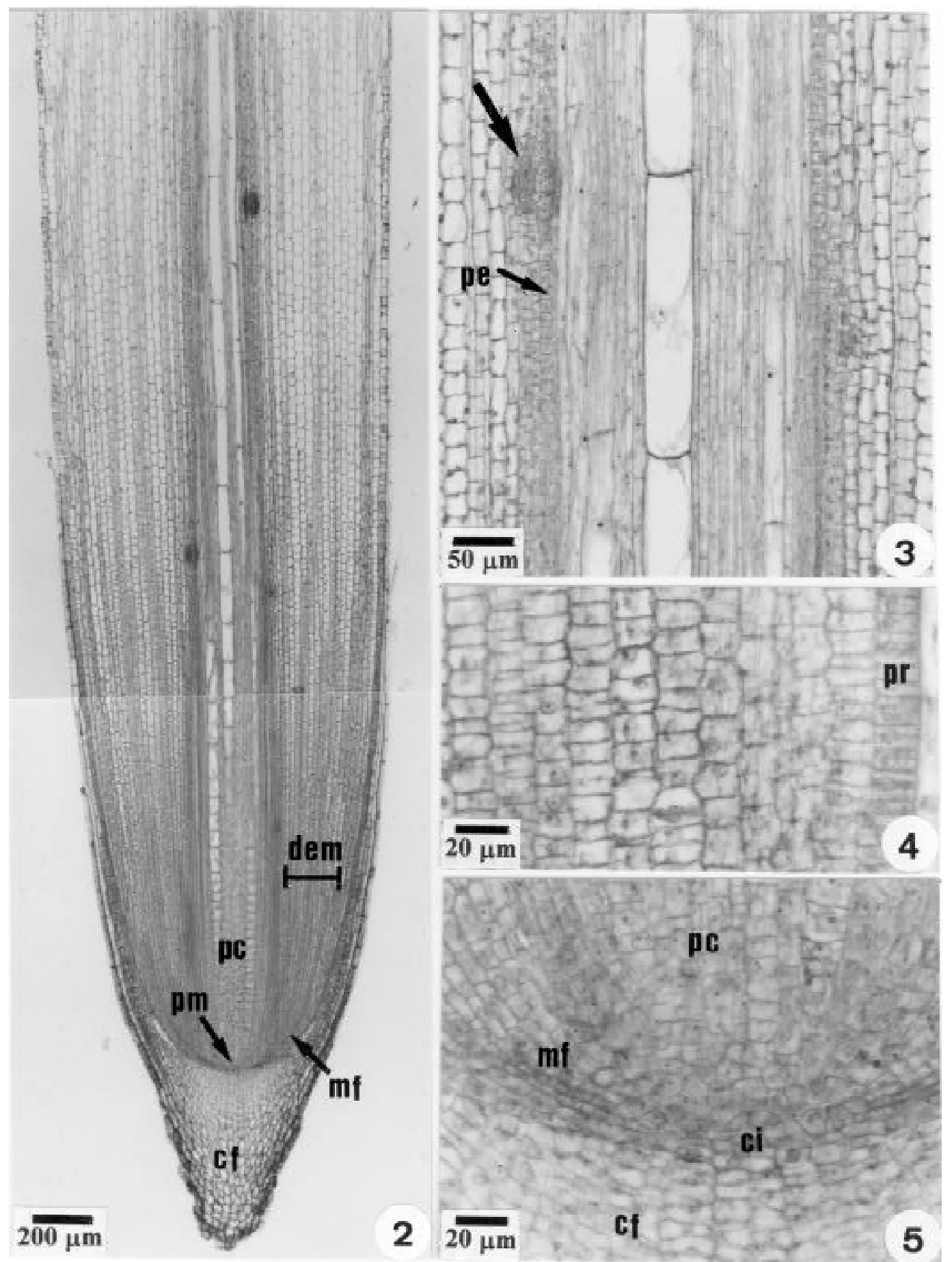

Figuras 2-5. Secções longitudinais medianas do ápice radicular de Canna edulis Kerr-Gawler. 2. Aspecto geral do ápice com células iniciais do pró-meristema (pm), células derivadas componentes do meristema fundamental (mf), derivadas da endoderme meristemática (dem), procâmbio (pc) e coifa (cf). 3. Detalhe da região do cilindro vascular mostrando periciclo (pe) e primórdio de raiz lateral (seta). 4. Detalhe da protoderme (pr). 5. Detalhe das células iniciais do pró-meristema (ci), meristema fundamental (mf), procâmbio (pc) e coifa (cf).

células do córtex, sofrem divisões anticlinais indicadas (seta 1, Fig. 8). A seta 2 nesta mesma Figura 8 indica uma célula pericíclica em processo de divisão anticlinal. No nível representado nas figuras 9 e 10 , a $1400 \mu \mathrm{m}$ do pró-meristema, já se observam as células do córtex em processo de diferenciação adiantado, com espaços intercelulares definidos.

Essas características são melhor observadas nas Figuras 11 e 12, a $1700 \mu \mathrm{m}$ do pró-meristema, sendo possível ver na Figura 11 que as camadas resultantes 


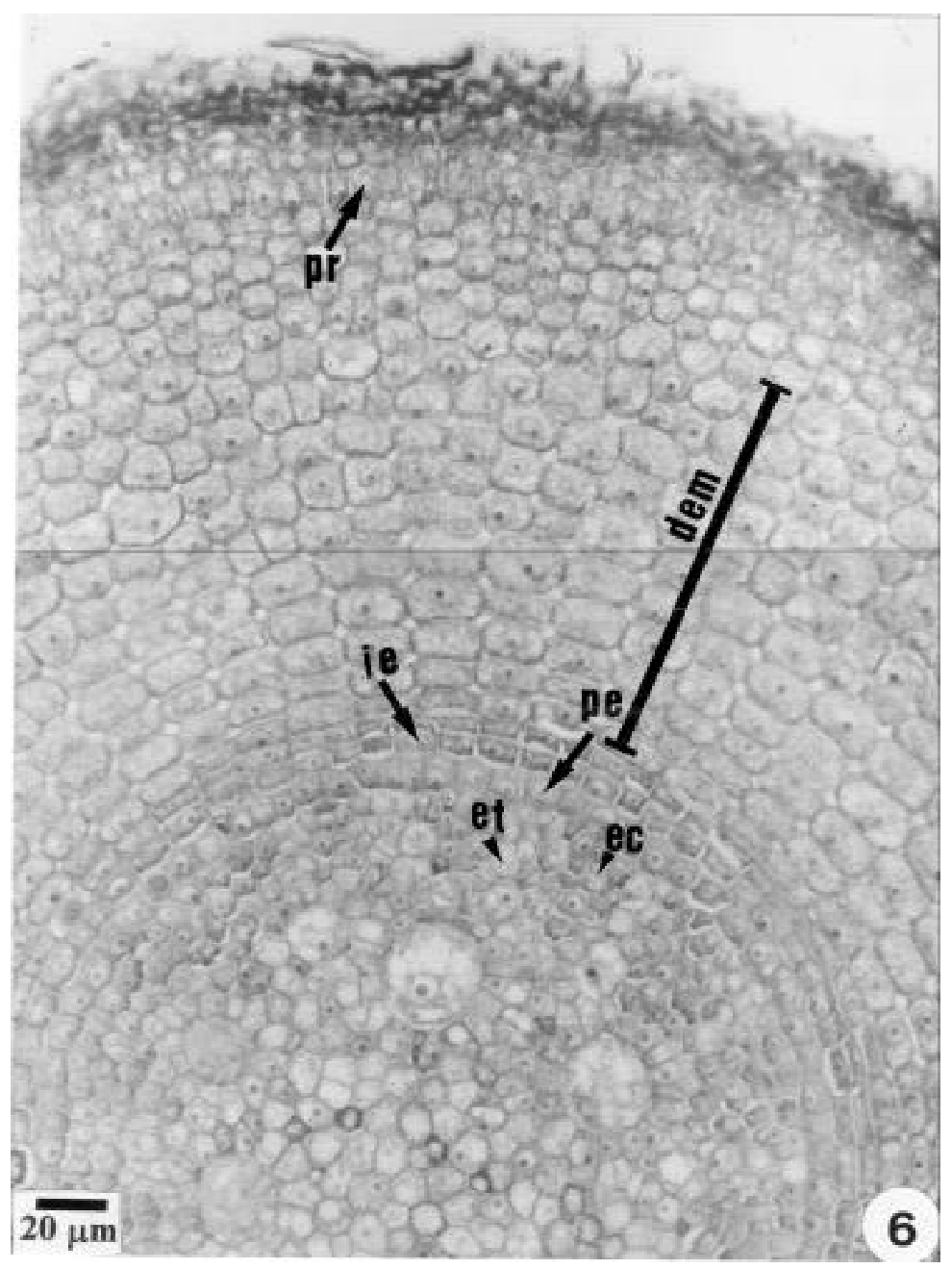

Figura 6. Secção transversal do ápice radicular de Canna edulis Kerr-Gawler a 220 $\mu \mathrm{m}$ do pró-meristema mostrando inicial endodérmica (ie), periciclo (pe), protoderme (pr), derivadas da endoderme meristemática (dem), elemento traqueal (et) e elemento crivado (ec).

da endoderme constituem mais de $2 / 3$ do córtex. Abaixo da epiderme encontram-se 3-4 camadas de células menores originadas diretamente do meristema fundamental (Fig. 11). Na Figura 12, verifica-se também o aparecimento de estrias de Caspary.

O periciclo (Fig. 12) é constituído por células de formato variado, dispostas em um cilindro contínuo. A raiz é poliarca, apresentando diferenciação exarca dos elementos traqueais. Alternando-se com o protoxilema, observam-se elementos floemáticos em diferenciação. O centro do órgão é ocupado por células parenquimáticas de formato isodiamétrico, constituindo a medula (Fig. 11 e 12).

\section{Discussão}

Em C. edulis o meristema fundamental dá origem às células das camadas mais externas do córtex, sendo as camadas mais internas originadas por uma endoderme com atividade meristemática. Tais resultados diferem do observado por Seago et al. (2000) que, ao descreverem o desenvolvimento cortical das raízes adventícias de Pontederia cordata, relataram que todos os tecidos corticais nessas raízes são originados do meristema fundamental.

No início do desenvolvimento em raízes de angiospermas Williams (1947) observou que as células do córtex ao redor da região de origem procambial, por ele denominada de "pleroma" e que se diferenciam em endoderme posteriormente, atuam como câmbio verdadeiro, originando os tecidos da região cortical dessas raízes em plantas vasculares. Portanto, para esse autor toda a região cortical situada entre a hipoderme e a endoderme tem origem na endoderme com atividade meristemática.

Hurst (1954 apud Van Fleet 1961) denominou de 


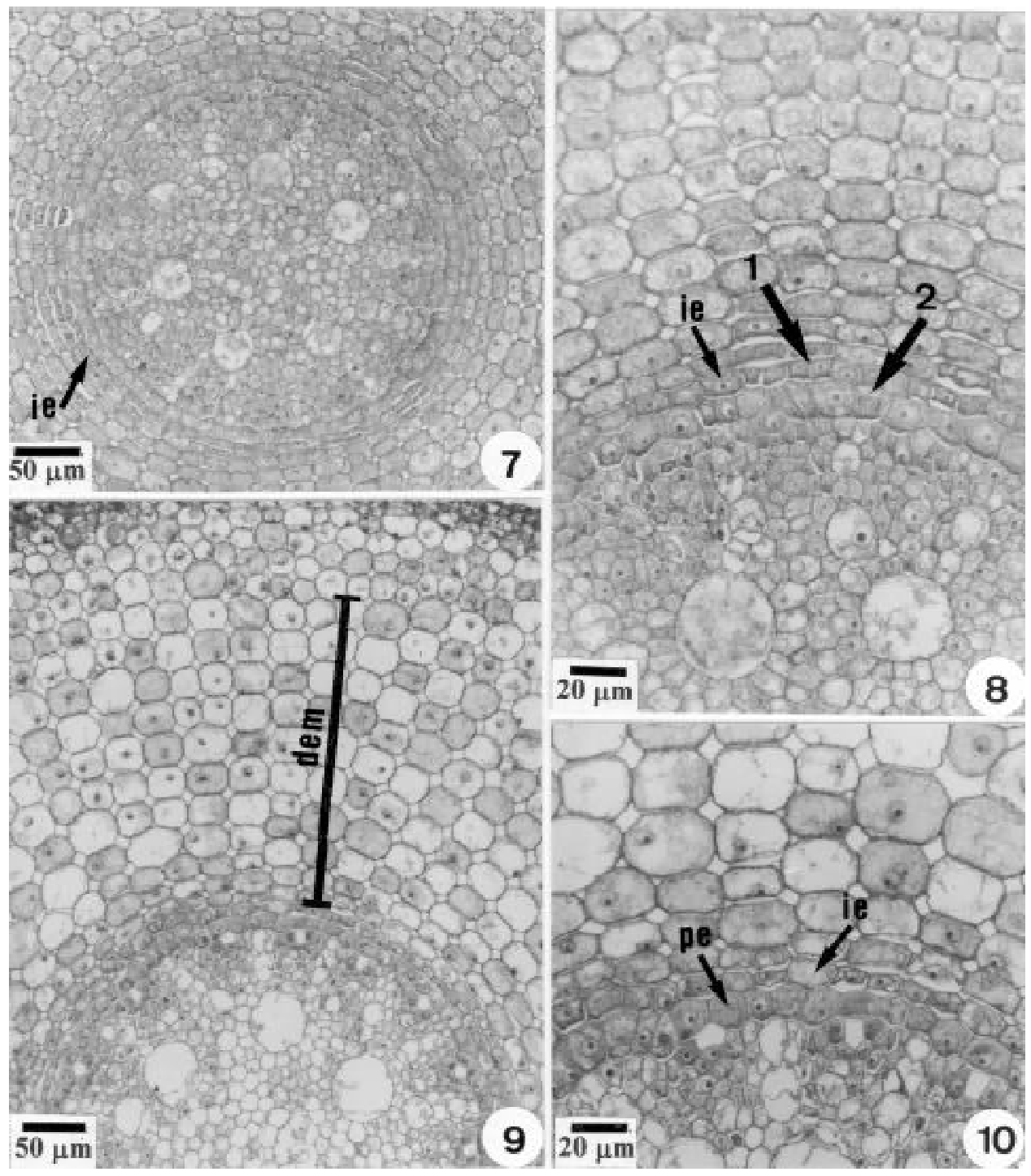

Figuras 7-10. Secções transversais do ápice radicular de Canna edulis Kerr-Gawler. 7. Inicial endodérmica (ie) originando fileiras radiais de células por divisões periclinais a $450 \mu \mathrm{m}$ do pró-meristema. 8. Detalhe da Figura 7 mostrando célula inicial da endoderme dividindo-se periclinalmente (ie), iniciais da endoderme em divisão anticlinal (seta 1) e do periciclo em processo de divisão (seta 2). 9. Aspecto geral do córtex a 1.400 $\mu \mathrm{m}$ do pró-meristema com células derivadas da endoderme meristemática (dem). 10. Detalhe da Figura 9 destacando-se periciclo (pe) e inicial endodérmica (ie).

proendoderme a fase meristemática inicial no desenvolvimento da endoderme. Ao descrever a estrutura anatômica das raízes de Canna indica L., C. coccinea Link e $C$. orientalis Bouche, Tomlinson (1961) relatou que o córtex é constituído por camadas de células periféricas pequenas e suberizadas, definindo camadas de células subjacentes dispostas em fileiras radiadas e concêntricas como sendo córtex interno.

A disposição radial das células do córtex interno parece ser característica comum às raízes das espécies de Zingiberales, como relatado para $C$. indica, C. coccinea e $C$. orientalis (Tomlinson 1961). Esse tipo de disposição anatômica foi observada também no córtex radicular de Musa acuminata cv. Gros
(Riopel \& Steeves 1964), Musa rosaceae Jacq. (Alquini \& Morretes 1996); Heliconia angusta Vell. e H. velloziana L. Emygd (Simão \& Scatena 2001). Porém, nesses trabalhos, esse tipo de organização celular não é atribuído à atividade meristemática da endoderme, enquanto em C. edulis, a disposição radial e concêntrica das camadas corticais internas é interpretada como resultante da atividade meristemática da endoderme.

Resultados semelhantes aos descritos para C. edulis no que se refere à atividade meristemática da endoderme, foram também relatados por Menezes et al. (2003) para raiz de Cyperus papirus L., Lagenocarpus Nees spp., Cephalostemon 


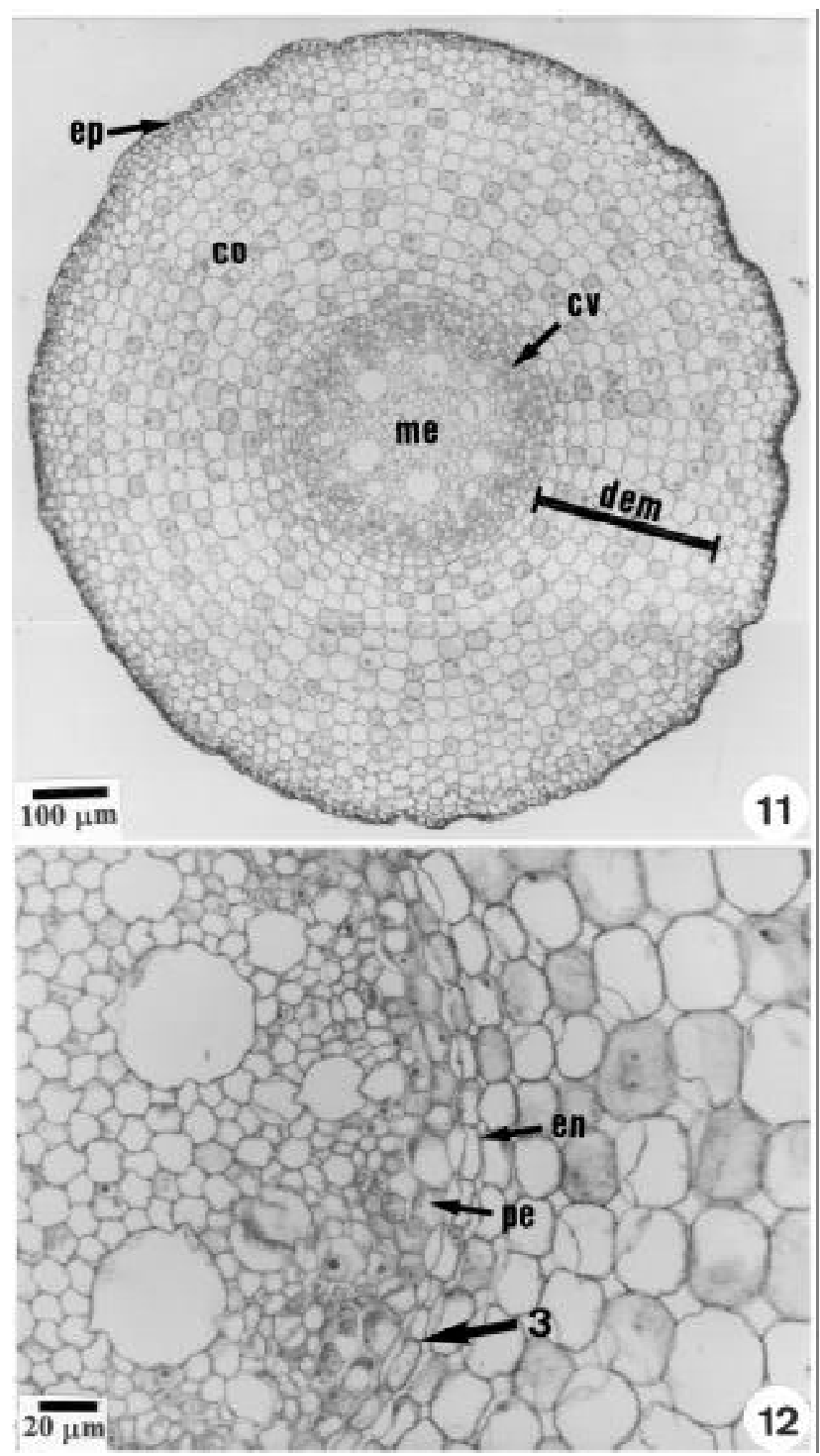

Figuras 11-12. Secções transversais da raiz em estrutura primária de Canna edulis Kerr-Gawler a $1.700 \mu$ m do pró-meristema. 11. Aspecto geral da raiz evidenciando a epiderme (ep), células do córtex (co), derivadas da endoderme meristemática (dem), cilindro vascular (cv), onde se destacam células da medula (me). 12. Detalhe da Figura 11 mostrando endoderme (en) com estrias de Caspary (seta 3) e periciclo (pe).

riedelianus Koern, Zingiber officinale Roscoe e Echinodorus panicullatus (Mart.) Buchenan que verificaram a presença de uma endoderme com a mesma atividade, denominando de iniciais endodérmicas as células geradoras das fileiras radiais do córtex. Essas autoras denominaram MED (Meristematic Endodermal Derivatives) as camadas resultantes da atividade meristemática, demonstrando que elas podem constituir todo o córtex (Cephalostemon riedelianus), a maior parte do córtex (Cyperus papirus) ou só a porção interna do córtex (Zingiber officinale).
Por meio da análise anatômica da região apical, conclui-se que na raiz adventícia de $C$. edulis, a disposição radial das células corticais é resultante da atividade meristemática da endoderme, cujas células dão origem a 2/3 do córtex, e o restante das camadas corticais externas são originadas diretamente do meristema fundamental.

\section{Agradecimentos}

À Coordenadoria de Aperfeiçoamento do Pessoal de Ensino Superior (CAPES), pela concessão da bolsa de Mestrado ao primeiro autor; aos membros do grupo de Agricultura do Centro de Raízes e Amidos Tropicais (CERAT), pelo fornecimento de material vegetal.

\section{Referências bibliográficas}

Alquini, Y. \& Morretes, B.L. 1996. Organização estrutural da raiz de Musa rosaceae Jacq. (Musaceae). Arquivos de Biologia e Tecnologia 39(3): 657-669.

Castro, C.F. 1995. Inter-relações das famílias das Zingiberales. Revista Brasileira de Horticultura Ornamental 1(1): 2-11.

Cronquist, A. 1981. An integrated system of classification of flowering plants. Columbia University Press, New York.

Dahlgren, R.M.T.; Clifford, H.T. \& Yeo, P.F. 1985. The families of the monocotyledons: Structure, evolution and taxonomy. Springer-Verlag, Berlin.

Gerrits, P.O. 1964. The apllication of glycol metacrylate in histotechnology: some fundamental principles. Leica GmbH, Germany.

Graven, P.; Koster, C.G., Boon, J.J. \& Bouman, F. 1997. Functional aspects of mature seed coat of the Cannaceae. Plant Systematics and Evolution 205: 223-240.

Karnovsky, M.J. 1965. A formaldehyde-glutaraldehyde fixative if high osmolality for use in electron microscopy. Journal of Cell Biology 27: 137-138.

Kress, W.J. 1990. The phylogeny and classification of the Zingiberales. Annals of the Missouri Botanical Garden 77(4): 698-721.

Menezes, N.L.; Silva, D.C.; Arruda, R.C.O.; Cardoso, V.A.; Melo-De-Pinna, G.F.; Yoshitake, A.M.A.F., Castro, N.M.; Scatena, V.L.; Dias, E.S. \& Cattai, M.B. 2003. A new interpretation of primary thickening in monocotyledons: meristematic endodermis and pericycle. Proceedings of the Monocots III and Grasses IV Conference California. (no prelo).

O’Brien, T.P.; Feder, N. \& McCully, M.E. 1964. Polychromatic staining of plant cell walls by toluidine blue. Protoplasma 59(2): 368-373.

Pérez, E.; Lares, M. \& González, Z. 1997. Some caracteristics of sagu (Canna edulis Kerr) and zulu (Maranta sp.) rhizomes. Journal of Agricultural and Food Chemistry 45(7): 2546-2549. 
Riopel, J.L. \& Steeves, T.A. 1964. Studies on the roots of Musa acuminata cv. Gross Michel. 1. The anatomy and development of main roots. Annals of Botany 28(111): 475-490.

Seago Jr., J.L.; Peterson, C.A. \& Enstone, D.E. 2000. Cortical developmental in roots of the aquatic plant Pontederia cordata (Pontederiaceae). American Journal of Botany 87(8): 1116-1127.

Simão, D.G. \& Scatena, V.L. 2001. Morphology and anatomy in Heliconia angusta Vell. and H. velloziana L. Emygd. (Zingiberales: Heliconiaceae) from the Atlantic forest of southeastern Brazil. Revista Brasileira de Botânica 24(4): 415-424.
Tomlinson, P.B. 1961. The anatomy of Canna. Journal of the Linnean Society of London (Botany) 56(368): 467-473.

Tomlinson, P.B. 1962. Phylogeny of the Scitamineae: morphological and anatomical considerations. Evolution 16: $192-213$

Tomlinson, P.B. 1969. Commelinales-Zingiberales. Pp. 295-421. In: C.R. Metcalfe (ed.). Anatomy of the monocotyledons. Clarendon Press, Oxford.

Van Fleet, D.S. 1961. Histochemistry and function of the endodermis. Botanical Review 27(2): 165-220.

Williams, B.C. 1947. The structure of the meristematic root tip and origin of the primary tissues in the roots of vascular plants. American Journal of Botany 34(9): 455-463. 